\title{
An Analysis of Management Development in the Hotel Sector Using the Grounded Theory Approach - A Case Study of Mauritian Hotels
}

\author{
Needesh Ramphul", Hemant Chittoo \\ School of Business, Management and Finance, University of Technology, Mauritius
}

Copyright (C) 2015 by authors, all rights reserved. Authors agree that this article remains permanently open access under the terms of the Creative Commons Attribution License 4.0 International License

\begin{abstract}
Management development is vital for ensuring the competitiveness of an organization. However, few studies have been carried out to understand the actual process of developing managers within the hotel sector in Mauritius. The purpose of this paper is to understand the way in which management development is being done within the Mauritian hotel sector. A grounded theory approach was used since little research has been carried out on this aspect in Mauritius. In this context, 27 designers (human resource and training managers) from Mauritian hotels were interviewed to get relevant information on the management development process. The research enables to come up with a new conceptual framework on the management development process based on the views of designers. The conceptual framework helps to understand the actual process of management development within the Mauritian context.
\end{abstract}

Keywords Grounded Theory Approach, Management Development, Mauritian Hotels

\section{Introduction}

Organizations need competent managers to reach their objectives, Boyatzis,[3].One of the ways to get competent managers is by investing in management development. Management development includes the processes through which an organization ensures that its managers have the necessary skills, knowledge and do their work and cope with organizational and environmental change, Lees,[13]. It goes beyond management education and training, Lees,[13], O Connor and Mangan,[18]. In addition to formal seminars and on the job training, it also involves informal coaching and mentoring to facilitate learning. The Karpin report done by the Australian Institute of Management,[2] raised awareness of the relationship between management capabilities at all organizational levels and company performance. It highlighted the critical importance of education, training and ongoing professional development to ensure that managers had the knowledge and skills needed to perform effectively. This report also emphasized the importance of non-technical domains of management such as: leading and managing people, communicating, negotiating, resolving conflict, fostering creativity and innovation, and managing change. Mabey C and Ramirez M, [14] surveyed 179 companies across six European countries; the UK, France, Germany, Spain, Denmark and Norway to assess the impact of management development on organizational productivity. The main finding was that MD leads to superior organizational productivity only if line managers perceive that their organization is highly committed to MD policies in terms of ethos and practices.

Although there is a growing interest in research in terms of Management development on the international context, no such research has been carried out within the Mauritian Context. The tourism sector is considered as the third pillar supporting the Mauritian economy and it has been an important contributor to the economic growth and development of Mauritius. However, the sector has to face several challenges due to growing competition from other tourist destinations and financial problems in the European countries which are the main markets for the Mauritian hotel sector. The Mauritian hotels have been compelled to diversify their traditional markets and tap into emerging markets like India and China. However, for such strategy to be successful both line staff and managers have to develop new know how to better serve these new customers. On the other hand, the Mauritian government is trying to increase the number of tourist arrivals in future and this may also mean that expansion of the sector will lead to an increase in the demand for managers in the hospitality industry. The main purpose of this paper is to enable both academics and 
practitioners to better understand the actual way in which managers are being developed within the Mauritian hotel sector and this may in future help to improve the process to meet the new business context. It may also enable other countries to learn from the Mauritian experience and improve their own tourism sector in case they have a similar situation.

\section{Management Development within the Tourism Sector}

According to the World Travel and Tourism Council,[25], the travel and tourism industry generated account for $9.5 \%$ of global GDP and 266 millions of jobs . Managers represented $29 \%$ of those employed in this industry and they are considered vital for the development and productivity of the sector. In the UK, there has been a problem attracting, developing, and retaining managers in the travel and tourism sector ,Kent,[11]. This has led to UK research in the management development field to try to understand this issue. Many studies have also been carried out in other countries to understand the management development process in the hospitality and tourism sector. A recent review by Sandra Watson [24] identified different themes that management development has emphasized in the hospitality and the tourism sector. This provides an overview of the aspects of management development that may be important for this specific sector.

Management development in the hospitality and tourism sector is impacted by both internal and external factors. The internal factors include: the type of organisation, its policies and procedures, and the HRM practices of the organisation. These factors affect management development and can explain the contextual nature of the process, Mabey,[15]. On the other hand, sector characteristics also have an important factor impacted on management development practices. For example, as the diversity of organisational types, their size, ownership and geographical spread within an industry is more varied, this can result in differing operating systems and a variety of managerial practices, Slattery,[20]. The hospitality and tourism industry also has long, asocial working hours, low pay, unfavourable working conditions, low skills and a lack of career opportunities and these factors should be considered while persuading future managers to join this industry. Other external factors that can influence the management development process include the local social and political values, and environmental and technological factors, Mabey,[15] .

The local educational system is very influential in shaping management development practices in the hospitality and tourism sector. Traditionally, the vocational system was used to develop cadres to meet sector needs but with institutions under pressure to cut costs, food and beverage aspects of the industry as well as other practical features have been eliminated, Alexander, [1]. In addition, general management content is being included into the tourism curriculum, providing program content that is less applicable to the industry's specific needs. Internships are important for graduates to get a practical feel of the hospitality and tourism sector and to develop related skills and competence.

The management development literature has focused on hospitality and tourism and identified the skills and competences managers in this particular sector need. An issue is the balance between the operational and managerial aspects of the hospitality management. It seems that operational skills are more important than management skills for middle and first line managers, Brophy and Keily,[4]. However, management skills are also vital for success in middle management positions. Ladkin and Juwaheer,[12], for example, point out how operational Food and Beverage knowledge and experience is important for being promoted in a general management position. For general managers, general business skills may be more important than operational/technical skills since tourism has becoming highly competitive and requires management like any other business, Harper et al,[10]. This implies that students and managers should develop business and management competencies and abilities including global exposure, an orientation to customer service, and an awareness of financial management issues, market trends, innovation in the industry, a commitment to work, leadership skills and an ability to adapt and change.

Another theme involves management career development. Management advancement is considered to be an outcome of management development and hence, it will influence the content of management development programs. Garavan et al [8] considered "investment in training and education, mentoring, networking, experience and competencies, and individual commitment to advancement as being important in enhancing careers." Career mobility in addition to international experience and international qualifications are also important for acquiring general management positions in the hotel industry, Ladkin and Jawaheer,[12] .

Harper et al,[10] found that there is a reduction in the emphasis on food and beverage knowledge that is required in order to get general management positions in the hotel industry. Managers having management qualifications, for example, achieve general management positions more quickly than those without such qualifications. On the other hand, the importance of food and beverage knowledge and knowledge in other technical areas is still important for getting general hotel management positions, Garavan et al, [8], Ladkin and Jawaheer,[12]. Many hospitality graduates take first line management or supervisory positions in order to get the needed knowledge and experience and with time, they hope to develop their career either within the particular hotel or outside it, Ladkin,[12]. These issues affect the design of management development programs as having appropriate content including general management and technical aspects reflective of local situations can help motivate managers to participate. Then, management 
development programs can be seen as way to meet career development objectives for sector managers.

In the hospitality industry, management development occurs at the start of a career in the sector and it is usually not well-organised and done on a piece-meal basis, Watson,[24]. Moreover, management development practices are closely linked to business goals and objectives. Performance appraisal and assessment centers are also widely used to determine the management development needs. The evaluation of management development practices is mainly done to show the benefits of the process to the individual (in terms of career advancement) and to organization (in terms of achieving business objectives). However, it is difficult to evaluate the immediate impact of management development on an organization or what the long term benefits may be. There is a firm belief that experiential learning is the best way to develop managers and have them learn directly from their work environment. There is an emphasis on action learning to support collaboration between educational institutions and the hospitality sector and industry.

\section{Research Methodology}

\section{Qualitative Research Methodology}

Management studies can be based on quantitative and/or qualitative methods. The choice of an appropriate method depends on the research objectives. According to Eisenhardt,[7], qualitative research methods are appropriate for studies in which no particular hypothesis is to be tested but instead, the research tries to identify relevant variables that may be important in a particular situation and generate new ideas and theories including hypotheses about how thing unfold over time in an area. She refers to this as theory building research and her ideas are similar to the Grounded Theory approach to building theory advocated by Glaser and Strauss, [9] for use when there is little knowledge about how things occur. A grounded theory approach treats research findings as emergent and the data collected helps develop new insights, findings and eventually theories. When developing grounded theory, a researcher generates ideas based on the data emerging from the situation. Theory emerges as researchers see patterns in the emerging data, Glaser \& Strauss, [9]; Strauss and Corbin, [22].

Qualitative methods are also appropriate when the "purpose is to learn from the participants in a setting or process the way they experience it, the meanings they put on it, and how they interpret what they experience", Morse and Morse, [17]. The idea is that participants represent and explain their perspective on a particular process and researchers accept this perspective and do not impose their own interpretations on the participant's perspective. Such an approach allows a researcher to understand how those participating in a situation perceive a particular process or situation. Qualitative methods are also appropriate if the aim of the research is to find the meaning attributed to a situation by groups of individuals, Strauss and Corbin,[22] . According to them, the theory that is derived from the data collected from the field, explains how a phenomenon actually takes place than when using other peoples concept or speculation about a specific situation. To find out these perspectives, in-depth interviews were carried out with the designers of management development programs in the hotel sector. A Grounded Theory approach enabled the development of a model of management development and key related issues based on the interview information that is directly relevant to Mauritius.

There are three main versions of the grounded theory approach. The first one is that of Glaser and Strauss, [8] , the second one is that of Strauss and Corbin,[21] and the third one is that of Chamaz ,[5]. According to Glaser, the researcher under the grounded theory approach should not do a literature review first since it will influence the theory building process. According to him, the theory has to be completely derived from the data collected on the field. He also disagreed to the fact that the research will have prior research questions since research questions and problems are discovered when the data is being coded. However, Strauss and Corbin,[22] do not agree with the views of Glaser,[9] since they believe that the researcher should have some exposure to the literature as they can refer to it when the need arises. In addition, Strauss and Corbin,[22] think that prior research questions have to be developed as they can set boundaries to the study area. For the purpose of this study the version developed by Strauss and Corbin,[22] has been used since I reviewed the literature of Management development in General and within the hotel sector and based on the research Gap, research questions have been developed. The research questions effectively set the boundaries under which the whole study has been carried out.

\section{Informants}

Informants are people chosen because based on their experience they can provide information about Mauritian management development processes and situations. More specifically, the informants will be people who have either designed or participated in management development programs offered within the Mauritian hotel sector. Management development program designers usually include specialist training and learning managers or human resource managers, assistant human resource managers, quality assurance managers and general managers, Thompson et al,[23]. The intention in this study is to ask these managers how they identify the developmental needs, how they satisfy these needs and how they can improve the design of management development programs in future.

I have used my network to get in contact with the human resource managers and training managers working in the hotel sector. Students at the university also helped to get access since many part-time students work in the hotel sector. In addition, using snowballing sampling, Miles and Huberman, [16], I asked human resource managers I have 
interviewed for contacts in other hotels and for introductions to first-line or middle managers working in their own hotel.

\section{Theoretical Sampling}

Population

The population defines a set of characteristics from which a research sample is drawn, Eisenhardt,[7]. In addition, the population defines limits for the generalization of any findings. For the purposes of this research, the relevant population includes the designers in management development programs in the 118 hotels in Mauritius.

\section{Key Aspects of Theoretical Sampling}

According to Glaser and Strauss [8], when one pursues grounded theory, one chooses cases for theoretical reasons, i.e., to make sure all of the characteristics in the population are represented in the sample. The aim, then, is to make sure all theoretical categories and polar types from the population are included in the sample, Eisenhardt,[7]. For example, theoretical sampling dictates that the researcher chooses participants who have directly experienced the phenomena under study. By proceeding in this way, the researcher includes relevant 'experts' who are able to provide the best data available, Corbin \& Strauss, [22]; Glaser \& Strauss, [8]. The process of selecting participants is also an evolving process based on the evolving patterns, categories and dimensions that emerge as a result of gathering data. Specifically, researchers seek out participants who can provide deeper insights into the emerging patterns, categories and dimensions that become apparent in the sampling process. The same process was used in the context of this study and the data collected was analysed at the same time as the research progressed so that new themes, categories can be identified and verified with other people selected as the sample for the study.

\section{Sample Size}

Grounded theory also requires collection of enough in-depth data to identify patterns, categories, concepts, properties, and dimensions of the phenomenon of interest, Glauser and Strauss, [8]; Strauss and Corbin,[22]. Ultimately, the researcher determines the sample size that provides enough data to sufficiently describe the phenomenon. Usually, theoretical saturation is what determines the sample size. That is, the researcher continues to expand the sample until data collection reveals no new insights into population characteristics.

In a study based on interviews, then, there is no set sample size at which theoretical saturation can be expected to occur, Glauser and Strauss, [8]; Strauss and Corbin, [22]. Rather, the appropriate sample size is likely to vary depending on the scope of the research question and the ability of the researcher to get relevant data. Although there is no definite sample size in the Grounded theory approach, I have interviewed 27 designers (i.e,human resource / training managers). I have found that I reached theoretical saturation since I was not getting any new category and subcategories. Riley [19] claims that most studies achieve theoretical saturation between 8 and 24 interviews but this will depend on the research area although such statement can be against the concept of theoretical sampling. Most of the hotels were beach hotels and a few were business hotels located in the urban areas. There was also a mixture of big, small and medium sized hotels.

\section{Interview}

The main tool for primary data collection was an in-depth interview. I audio taped the interview after informants gave me permission to do so. Audio taping was necessary since it would be very difficult to take sufficient notes to record everything informants say concerning their perspectives on management development. It also enabled me to maintain good eye contact with the informants and to respond appropriately if difficulties emerge. Audio taping also helped in the analysis after the interview for the taped record ensured that no important data was missed out. The contents of the interview were transcribed verbatim so as to be able later to identify categories that informants used to explain their perspective. This is in line with the suggestions of Glaser and Strauss [8] who argue for collection, coding and analysis of data concurrently.

I personally interviewed the human resource/training managers. I used a semi-structured interview and I probed for more information on any unexpected issues that came up in interviews. The duration of all the interviews was between 30 minutes to one hour and the informants answered the questions in the interview guide during these durations. In some cases, I had to leave the semi structured interview guide since the manager told me that they were busy and they will send me the answers by email. These were also accepted since it provided the views of designers on the management development process prevailing in the Mauritian Hotel sector.

\section{Data Analysis}

In a grounded theory study, the researcher concurrently collects and analyzes the data, Glaser and Strauss,[8]; Miles and Huberman,[16]. This ongoing process enables the researcher to constantly identify emerging themes, issues that need further probing in future interviews and to confirm or reject emerging themes. In addition, this process also determines when one reaches a point of theoretical saturation.

I have used the steps proposed by Miles and Huberman [16] to analyse the interviews and field notes that I gather from the designers of management development programs in the Mauritian hotel sector. Miles and Huberman[16] suggest that qualitative data analysis should consist of three concurrent activity flows: data reduction, data display, and conclusion drawing and verification processes.

\section{Coding of Data}

According to the grounded theory approach, Strauss and 
Corbin, [22], data analysis is performed through a continuous coding process and there are three main types of coding namely open, axial and Selective coding.

\section{Open Coding}

First, an open coding of the data is performed. At this stage, the data gathered from the field was analyzed line by line in order to identify relevant themes and categories relevant to the management development process as it actually occurs in the Mauritian hotels. All the transcripts pertaining to different aspects of the management development process of both the designers were analyzed line by line using the NVivo 8 software and appropriate codes were allocated to each relevant aspect of the interview transcripts. The codes that were identified will represent concepts that will later become part of the theory.

\section{Axial Coding}

The second aspect of the analysis under the grounded theory approach is known as axial coding. In axial coding, the data is analyzed to see the relationship and links between the different categories/themes that were developed after the open coding process. In my context, I analyzed the links between the different types of categories and themes that come for management development process in the Mauritian hotel sector

\section{Selective Coding}

The coding process continues with selective coding. Selective coding aims at identifying the core category around which the theory will be built. The core category will act as the reference to all the other identified categories and it must be central in that all the other categories must relate to it and hence it must frequently appear in the data. Selective coding also tries to further develop categories into a theory since they merely describe the data that have been collected.

\section{Memoing}

During the whole process of data collection and analysis, the researcher will make notes of ideas, insights, questions that he may have about the researched area and in qualitative research this is known as the memoing process. This is a continuous process and it mainly occurs while the researcher is coding the data and the memos can help in building the theory as it emerges from the data. After doing the interview,
I made memos about what was the main aspect of the interview that was striking or new concerning the whole management development process. In addition, I also made memos while coding the data of the transcribed interviews and I highlighted main aspects that I will verify with next informant that I will investigate.

\section{Discussion}

\section{Axial Coding and the Theoretical Framework}

After carrying out the open coding of the data obtained, I analyzed the relationship that exist between the different categories that were developed and made connections between them. This is usually called the axial coding process. It is suggested to use a model so as to analyze the links between the different codes and the model includes the following aspects; causal conditions, the phenomenon itself, the context, intervening conditions, action/interaction strategies, and consequences. The causal conditions explain the factors that influence and lead to the central phenomenon. The phenomenon tries to explain the question about "what is going on here" and "what are the incidents, actions, and interactions that surrounds the phenomenon". It also looks into the people who are involved in the process, and how these people manage, influence and relate to the phenomenon. In the context, we try to look at the locations of events and where the phenomenon takes place. It also considers the time and stage at which the phenomenon can occur. On the other hand, the intervening conditions represent the actions that the people need to perform and this will help to shape and facilitate the strategies. Strategies represent the ways in which people address the phenomenon. They are usually purposeful and goal oriented. It is the strategies that help to achieve the outcomes and helps to meet the objectives that were set. The last part of the model will usually represent the consequences and these will represent the results of the actions and interactions and the outcomes of the strategies that were used. The following diagram represents the model that was developed after carrying out the axial coding process for the management development process in the Mauritian hotel sector. 


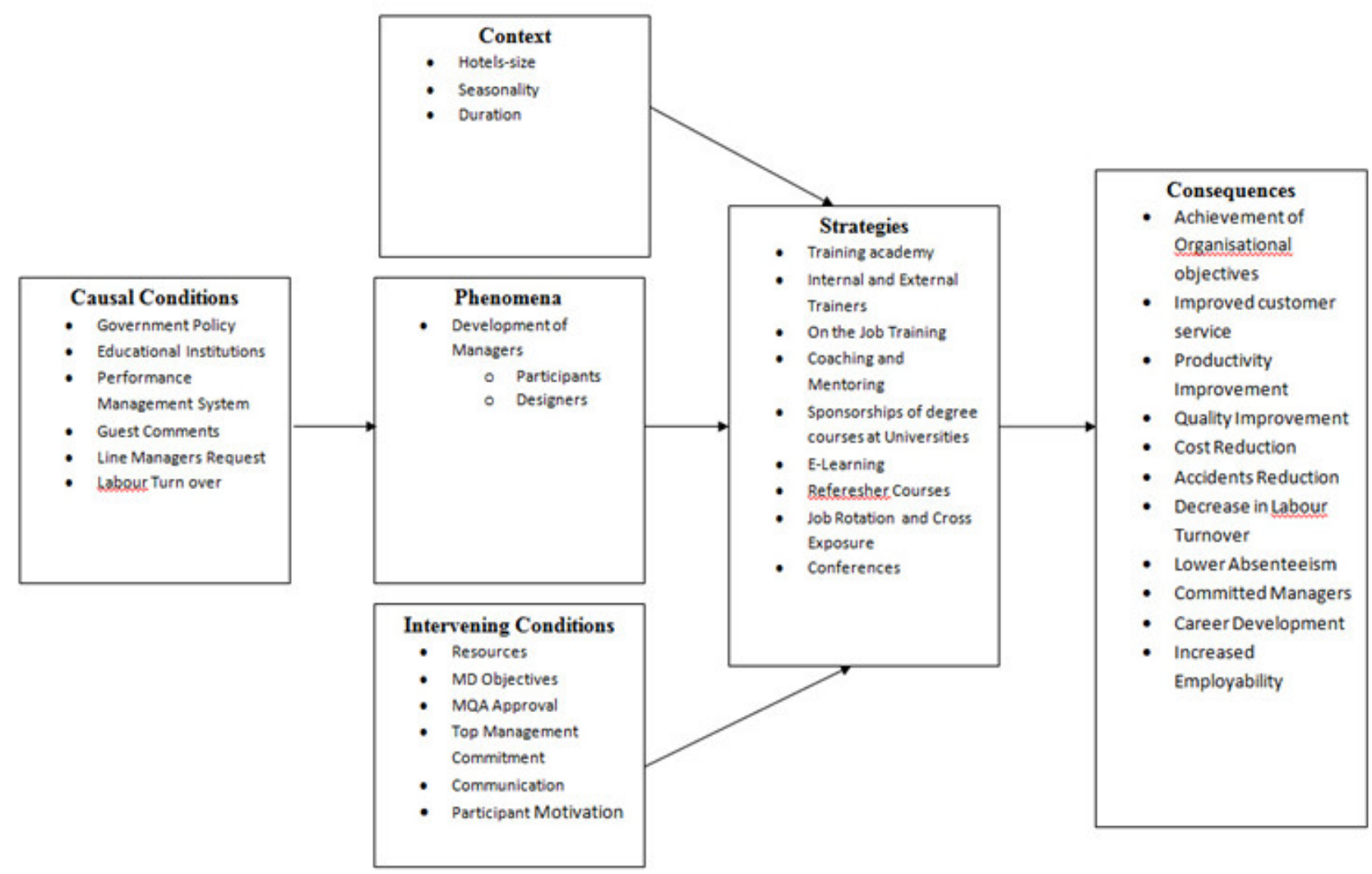

From the diagram, it can be seen that there are many causal conditions that lead to the phenomenon. The main phenomenon in this case is the management development process that takes place in the Mauritian hotels. One of the factors that lead to the MD process is the government policy. From the secondary data available it was shown that the government has devised policies in order to motivate organization to provide training to all employees including managers in the Mauritian organization. Mauritian organizations from the private sector including hotels have to compulsorily contribute to a training levy of $1 \%$ of their wage bill towards the HRDC and the organization can get a refund of $60 \%$ of any training and development programs costs that they organize. From the interviews, some of the designers voiced out that one of the reasons for organizing management development programs in hotel is to get the refund from the HRDC. On the other hand, government also organizes training in different areas and managers attend these training programs and this can also be included in understanding management development programs in the hotels. For instance the government has recently organized a conference for managers in hotels so that they can better understand the requirements of the new emerging markets like China.

Management education is a component of management development. In Mauritius, the government has created the hotel school of management so as to cater specifically for the training and development needs of the tourism sector. It provides courses both tailored for lower level employees and development of management skills for this sector. Many Mauritian hotels get their staff to work for them through these programs since they help to build skills relevant to the sector. Hence, they work in corporation with these educational institutions more specifically with the "Ecole Hôtelière Sir Gaëtan Duval" and the local universities by offering work placement opportunities to the students and if the students work well, they are also employed in the hotels. These collaboration processes also trigger the management development process in these hotels.

From the interview of designers of the management development programs in the Mauritian hotels, it was found that Mauritian hotels uses the performance management system in order to identify the main areas in which managers must be developed. The performance management system take into consideration the organizational objectives and strategies and translates it into individual objectives. Failure to achieve individual objectives usually highlights weaknesses of the managers and based on that appropriate development programs are designed and implemented.

It was also found that both small and large hotels rely a lot on customers' feedback in order to develop appropriate management development programs. Feedback from customers can be collected through different means such as customer complaints at the reception desk, filling customer satisfaction forms, customer surveys, mystery shoppers and through the reviews available on different websites such as 
trip advisors. Customer feedbacks help managers to know about their own weaknesses and that of those employees working under their supervision. On the other hand, financial crisis and economic problems in the European countries have implied that Mauritian hotels have to diversify their markets in order to reduce heavy reliance on European countries for their revenue. This has some major implications on the way both managers and employees are going to deal with customers coming from emerging countries like China and India and this has also triggered some management development programs being run in many Mauritian hotels.

Many designers also pointed out that management development programs are developed by taking into consideration the request of line managers in the Mauritian hotels. If the requests are justified and it will be helpful in improving the efficiency and quality of service then appropriate management development programs are developed. Most of these requests are voiced out during the performance appraisal interview or direct request are made by managers to their direct superiors. However, if the requests are not appropriate for the organization then these requests are not taken into consideration.

According to the interview carried out, it was found that in some hotels an increase in labour turnover rates can indicate problems related to the human skills of managers. Consequently, relevant management development programs can be designed so as to address these types of weaknesses on behalf of the managers.

\section{Main Phenomenon - Management Development Process}

The Main phenomenon for this thesis is the whole management development process as it occurs within the Mauritian Hotel sector. Research was carried out to identify and understand different aspects of the management development process in the Mauritian Hotel Sector. According to the literature Review, it was stated that many organizations invest in management development programs but they do not evaluate its effectiveness and its impact on the achievement of organizational objectives. In addition, organizations do not have clear objectives about investing in the management development process. Consequently, one aspect of the phenomenon that was probed into was the objectives of the management development process in the Mauritian hotels. The study also investigated the ways in which the developmental needs of the managers in the Mauritian hotels are identified and part of this is explained in the causal conditions. The ways in which the hotels satisfy the developmental needs that were satisfied were also investigated. I also investigated the ways in which the hotels evaluate the management development programs and what are the outcomes of the management development programs in these hotels.

Although there are different people who are involved with the process, only the designers were interviewed in order to get a deeper insight of the central phenomenon. They were appropriate since they are directly involved in the process and they provided their own perspectives of the central phenomenon of the research. It was found that there were agreements and disagreements about different aspects related to the management development process in the Mauritian hotel sector.

\section{Context}

The context in which the management development process is taking place is very specific and it impacts on the way the whole process is carried out. Apart from specific knowledge of the different operations, managers are required to have some practical know how and this is one of the reasons for managers being trained both in academic areas as well as practical development process. Fresh graduates from the university have to undergo a development program under a coach or mentor so as to substantiate the academic knowledge with real issues arising in the day to day management of a hotel in Mauritius. Moreover, most of the hotels in Mauritius are beach hotels and they are managed in a very specific way and this has to be taken into consideration before organizing development programs for managers. Cross exposure in different departments also enables managers to understand the interactions among different departments and see the overall contribution of their departments in the achievement of organizational objectives.

Mauritian hotels usually experience peak and off peak periods and the time frame of peak and off peak period is important to consider before organizing formal management development programs. For most Mauritian beach hotels, the off peak period starts in July till September. Most managers will prefer to attend formal management development programs during off peak period since they experience less pressure from the operations of the hotel activities. Many managers also voiced out that they do not like formal management development program whose duration is very long.

\section{Intervening Conditions}

Certain activities have to be carried out before the strategies can be used to address the phenomenon. In this context, the designers of management development programs in hotels must be able to secure resources in order to carry out these programs. They will usually have to prepare budgets and justify the budgets in front of top management so as to secure the necessary resources. After the identification of the management development needs, the hotels must set the management development objectives and the objectives will usually influence the strategies that will be used to carry out the management development activities in the Mauritian hotels. For instance, if the managers of the hotels already have the experience and the academic background and the main objective of the management development program is just to make aware about the recent changes and evolving trends in the specific area of operations then a refresher course will be more appropriate 
to meet these objectives. The management development objectives can also influence other aspects of the management development. Within the Mauritian context, some of the designers admitted that they organize management development programs in order to get refund of the training levy from the Human Resource Development Council. However, they can only get the refund if their management development program and the trainer is Mauritius Qualifications Authority (MQA) certified and at the same time their training academy is also MQA certified. In such circumstances, the designers will have to apply and present their development programs to the MQA before its implementation. In order to secure resources and get maximum participant involvement in the management development program, top management commitment in the Mauritian hotel is vital. The top management shows their commitment through their involvement by communicating the importance of the MD programs for the achievement of organizational and individual objectives. They also provide their full support to the designers of these management programs. Before starting the implementation of MD programs, the designers have to properly communicate the MD objectives and its importance to the participants. In the interviews, it was found that different means are used to communicate the required information about the management development programs. In order to make the strategies become successful, there should be high participant motivation or else the MD programs will not achieve its intended objectives. In the context of the Mauritian hotels, it was seen that some managers are not willing to participate in MD programs because they have already achieved a good position in the organization and for them, these programs are meaningless. Consequently, the designers must clearly explain the objectives and importance of the MD programs for the hotel.

\section{Strategies}

In this context, the strategies represent the way in which managers are being trained and developed in the Mauritian hotels. In most hotels, a mixture of ways are usually used to developed Mauritian Managers and on the job training remains the most used method in all these hotels. However, the strategies are also influenced by the size of the hotels and most evidently, big hotels and small hotels do not adopt the same strategies to develop their managers since they do not have the same resources. Big Hotels in Mauritius usually have their own training academy and training managers and this may not be the case for small hotels since they have more resource constraints when compared to the big hotels.

\section{Consequences}

After developing the managers in the Mauritian hotels, there are a lot of outcomes that emerges because of the strategies that are adopted. The strategies may have different consequences for the organization and the participants.

\section{Selective Coding}

After carrying out the axial coding process, selective coding is done. In selective coding the core category or categories are identified and it helps to explain the theory that has been developed. In this context, the core category is the management development objectives. Management development objectives help to understand the reasons for which Mauritian hotels are investing lot of money in the process and it is the objectives that influence the different aspects of the management development process. For instance, if the objective of management development process is to improve guest satisfaction and quality of service then analysis of customer feedback and reviews helps to identify the management development needs of the specific hotels and at the same time the outcomes of the management development process can be evaluated by again considering the feedback from customers. From this example, it can be seen that management development objectives help to determine the factors that will be considered in identifying the management development needs, the strategies that will be used to carry out the management development in the hotels and at the same time, the expected outcomes from the management development process and the way the outcomes of the management development programs can be evaluated. The management development objectives help to link the other aspects of the management development process and at the same time explain the way in which the whole management development process is being carried out in the Mauritian context.

\section{Verification of Information in the Models}

After the model was developed, it was shown to some of the people who were interviewed in the context of the research and other people who had lot of experience within the Mauritian Hotel sector. This was done to check whether it represented the actual process of Management development in the Mauritian hotels. Most of them agreed that the model reflected the actual process but there were some good comments from the people involved. For instance, instead of mentioning the time factor in the context, it was better to talk about the seasonality since they mentioned that there is a peak and off peak period in the Mauritian hotel sector and they to a large extent influenced the time period during which formal management development programs should be carried out.

\section{Conclusions}

The paper helps to develop a conceptual framework for management development as it takes place within the Mauritian context and it is based on the information provided by the designers of management development programs within the hotel sector. The grounded theory approach has got its own limitations as any other research methodology. One of the main limitations of this research is that it depends 
a lot on the views given by the informants on the management development process. The designers of management development programs may have given their perspectives of management development and not how management development really occurs in practice in the Mauritian hotel sector. In some cases the informants provide information that the researcher wants to hear in order to protect the image of the organization or to cover up for their weaknesses in developing these management development programs. On the other hand, other sources of data especially annual reports and government statistics and policies have also been probed into to ascertain whether the experiences of the informant are also reflected in these reports. In addition the views of other academics who have worked in the hotel sector were considered to check whether the model that has been developed made any sense about the real practice. All these aspects also helped to overcome the second limitation of grounded theory approach since many authors have pointed out that researchers confuse the grounded theory approach with the phenomenology approach. This was not the case here since the research has used different sources of data apart from the interviews of the informants and there was a lot of emphasis on the context rather than the stories of the informants.

This research can be improved in future. The research has enabled to develop a model and it enables other authors to use the model to develop certain hypothesis about management development in the hotel sector. They can use a quantitative approach to posit and test the hypothesis that can be developed. On the other hand, comparative studies can be done in other countries like La Reunion, Seychelles, and Maldives amongst others that have beach hotels and the differences and similarities in the way management development is done in these countries can be developed.

\section{REFERENCES}

[1] Alexander,M (2007), Reflecting on Changes in Operational Training in UK Hospitality Management Degree Programmes", International Journal of Contemporary Hospitality Management., Vol. 19 No. 3, pp. 211-20.

[2] Australian Institute of Management (2002), Management Development Practice in Australia, a National Study Commissioned by the Australian Institute of Management, Management Research Series No 1/2003

[3] Boyatzis, R.E (1982), The Competent Manager; a Model for Effective Performance, John Wiley and Sons.

[4] Brophy, M and Keily, T. (2002), Competencies: a New Sector Analysis, Journal of European Industrial Training, Vol. 26, pp. $165-76$

[5] Charmaz Kathy,(2006), Constructing Grounded Theory; A practical guide through qualitative analysis, Sage Publications
[6] Central Statistical Office report on International Travel and Tourism for the year 2013 (2014), Ministry of Finance and Development

[7] Eisenhardt, Kathleen (1989), Building Theories from Case Study Research, Academy of Management Review, Vol 14 No 4, pp. $532-550$

[8] Garavan,T , O’Brien, F. and O'Hanlon, D. (2006), Career Advancement of Hotel Managers Since Graduation: a Comparative Study, Personnel Review, Vol. 35 No. 3, pp. 252-80

[9] Glauser, B, \& Strauss, A. (1967), The Discovery of Grounded Theory: Strategies of Qualitative Research, London: Wiedenfeld and Nicholson

[10] Harper S, Brown C and Wilson (2005), Qualifications: a Fast -Track to Hotel General Manager?, International Journal of Contemporary Hospitality Management, Vol. 17 No. 1,pp. 51-64.

[11] Kent, M.C (2006), The Clock is Ticking. How Long Have we Got Before our Skills Time Bomb Goes Off?, available at: www.people1st.co.uk

[12] Ladkin, A and Juwaheer, T.D (2000), The Career Paths of Hotel General Managers in Mauritius, Journal of Contemporary Hospitality Management, Vol 12 No.2, pp.119-125

[13] Lees, S. (1992). Ten faces of management development. Management Education and Development, Vol 23, PP 89-105.

[14] Mabey, C. and Ramirez, M. (2005), Does Management Development Improve Organizational Productivity? A Six-Country Analysis of European Firms, International Journal of Human Resource Management, Vol 16, No 7, pp1067-1082

[15] Mabey, C. and Thomson A. (2000), Management Development in the UK: a Provider and Participant Perspective, International Journal of Training and Development, Vol 4 No.4, pp 272- 286.

[16] Miles M.B and Huberman A.M (1994), "Qualitative Data Analysis - An Expanded Sourcebook", second edition, Sage Publication

[17] Morse, J.M. and Morse, L.R. (2002), Read Me First for a User's Guide to Qualitative Methods, Sage Publications

[18] O’Connor, M., \& Mangan, J. (2004), Management Development in Ireland, Dublin: Irish Management Institute

[19] Riley, R. (1996), "Revealing socially constructed knowledge through quasi-structured interviews and grounded theory analysis", Journal of Travel and Tourism Marketing, Vol. 15 No. 2, pp. 21-40.

[20] Slattery, P.(2002), Finding the Hospitality Industry, Journal of Hospitality, Leisure, Sport and Tourism Education, Vol. 1 No. 1, pp. 19-28.

[21] Spradley, J.P. (1979), The Ethnographic Interview, Harcourt Brace Jovanovich College Publishers

[22] Strauss, A.L, and Corbin, J.M (1998), Basics of Qualitative Research: Techniques and Procedures for Developing 
Grounded Theory, ( $2^{\text {nd }}$ edition), Sage Publications, Thousands Oaks

[23] Thompson A.et al (2001), Changing Patterns of Management Development, Blackwell Publishing

[24] Watson, S. (2008), Where are We Now?, A Review of
Management Development Issues in the Hospitality and the Tourism Sector. Implications for Talent Management, International Journal of Contemporary Hospitality and Tourism Management, Vol 20 No.7, pp. 758-780

[25] WWTTC (2015), World Wide Travel and Tourism Council, available at: www.wwttc.org 